\title{
Effects of social change on wildlife consumption taboos in northeastern Madagascar
}

\author{
Christopher D. Golden $^{1,2}$ and Jean Comaroff ${ }^{3}$
}

\begin{abstract}
In Madagascar, the constellation of taboos serves as a form of informal regulatory institution and is foundational to Malagasy culture, regardless of class, ethnic group affiliation, and educational background. Many researchers have credited rapid social change as a crucial mechanism for disturbing taboos. Others suggest that taboos are innately historical. However, very little empirical research has assessed the effects of social change on taboos or quantified the stability of taboo systems over time. Here, we use a case study of the ensemble of taboos in northeastern Madagascar, still a critical aspect of social life there, as a lens through which we investigate its degree of stability over time. Our aim was: (1) to describe the food taboos of local Malagasy living in northeastern Madagascar, and (2) to quantitatively assess the stability of these taboos to address certain claims regarding cultural erosion using an empirical, hypothesis-driven approach with rich ethnographic material to aid in interpretation. We investigated the temporal stability of taboos and local adherence to the moral framework, finding that approximately $3.0 \%$ of 4857 taboos were not adhered to at least once during the course of a 7-yr follow-up study. Additionally, we quantitatively explored the mediating effects of migration, modernization, and the spread of Western religion on number of taboos and level of adherence. We found that the presence of extralocal groups and migration did not decrease the number of taboos abided by locally, but did increase rates of nonadherence. Modernization accompanied by generational shifts tended to increase rather than erode the number of taboos, and younger individuals adhered to taboos to the same degree as older individuals. The effect of Western religion depended on the denomination, but generally reduced the number of taboos, although it did not affect adherence. The ways in which social change affects the stability of taboos are complex. Migrants tended to adhere to taboos less than long-standing inhabitants, suggesting that attachment to place is significant in maintaining adherence to taboos.
\end{abstract}

Key Words: bushmeat; conservation policy; cultural change; hunting; immigration; migration; modernization; religion; wildlife

\section{INTRODUCTION}

Taboos in Madagascar, called fady, shape all aspects of Malagasy life and are fundamental to social behavior and cultural practice, regardless of ethnic group affiliation, socioeconomic status, or geographical difference (Ruud 1960, Sodikoff 2012). Although the ensemble of taboos is foundational to Malagasy culture (Ruud 1960), there has been little research on its stability over time, neither in form nor content, as a type of informal regulatory institution. Fortunately, there is rich anthropological literature in Madagascar to build upon that has recognized the dynamism of human culture and "rejected the idea that there is, or ever was, such a thing as an unchanging 'traditional society,' which was ... somehow only recently 'threatened' by history in the form of the 'modern world.' ...Malagasy history, culture, and society has been one undergoing radical change and transformation, [and] has never been still," (Bloch 2001:293-294). Given current trends in rapid economic (e.g., Minten and Barrett 2008) and political (Zounmenou 2009, Rakotomanga 2011) change in Madagascar, it is important to understand current patterns of social and cultural change as well. This is the first article of a two-part series. Here, we use a case study of the constellation of taboos in northeastern Madagascar, a critical aspect of Malagasy social life, as a lens through which we investigate the role of social change in affecting the degree of stability of taboos. In the second article (Golden and Comaroff 2015), we explore the possible human health and environmental conservation values of taboos.

The purpose of this study is twofold: to describe the wildlife consumption taboos of Malagasy living in northeastern Madagascar, and to address certain claims regarding cultural erosion through the lens of the Malagasy taboo system using an empirical, hypothesis-driven approach. As part of our exploration of the dynamism of taboos, we problematize persistent myths that the taboo system was once "intact" or more protective of the environment than it is currently. For example, Sodikoff (2012:69) directly connected social transformation and environmental degradation, asserting that animal taboos "are objects around which two extinction events converge: the one cultural (the loss of ancestral custom), the other biological (the loss of endemic species)." Our study complicates claims of cultural erosion and can be seen as an extension of Kull's (2000) and Horning's (2012) work, which critiqued ecological degradation myths.

Quantitatively, we investigate the temporal stability of taboos and local adherence to their moral framework. We also explore empirically the mediating roles of migration, demographic change, and Western religion in affecting taboos. Specifically, we conduct a multi-variable regression analysis of the socio-demographic correlates of taboos to address three common claims regarding traditional natural resource governance and exploitation: (1) immigration of extra-local groups negatively affects the stability of taboos (Durbin et al. 2003, Kaufmann and Tsirahamba 2006, Lilette 2006, Schachenmann 2006, Patel 2007, Rasolofoson et al. 2007, Gardner et al. 2008, Blanc-Pamard 2009, Scales 2011, Sodikoff 2012); (2) modernization causes cultural dissolution and erosion (e.g., Alcorn 1991, Chapin 1991, Gardner et al. 2008); and (3) Western religion and missionization cause deterioration of traditional spiritual beliefs, including taboos (e.g., Anoliefo et al. 2003, Lingard et al. 2003, Tengö et al. 2007, Gardner et al. 2008, Stifel et al. 2011). Implicit in many of these claims is the belief

${ }^{1}$ Harvard School of Public Health, Department of Environmental Health, ${ }^{2}$ Wildlife Conservation Society, Wildlife Health \& Health Policy, HEAL (Health \& Ecosystems: Analysis of Linkages) Program, ${ }^{3}$ Departments of African and African American Studies and Anthropology, Harvard University 
that taboos inherently protect conservation values (e.g., Anoliefo et al. 2003, Durbin et al. 2003, Schachenmann 2006, Gardner et al. 2008, Sodikoff 2012).

\section{BACKGROUND}

Madagascar is no stranger to massive religious, economic, and social transformation. However, while Madagascar's culture has never been static, the arrival of Europeans, Western religion, and the first missionary movements in 1506 marked especially forceful efforts to change its world from outside (Copland 1822). It is crucial to understand how these changes, from cultural and religious syncretism taking root to decades of colonialism, followed by socialism, global capitalism, and periods of violent political upheaval, may all have acted upon the reformulation of traditional informal institutions such as taboos. Over the course of the last century, migration has increased as the nation has become increasingly connected through a new transportation infrastructure and the burgeoning of regional and international economic opportunities (Zeller et al. 1999, UNDESA 2013). In addition, the population is rapidly becoming younger, with high rates of growth expected: $2.7 \%$ per year between 2015 and 2030 (UNDESA 2013). Each of these economic and social transformations could play a major role in altering the constellation of taboos.

Changes in environmental policy, closely tied to political change, also provide a crucial context for our study. During French colonial rule in the early 1920 s, a comprehensive system of national environmental legislation was codified to centralize the protection of environmental resources. Those laws were modified in 1960, post-independence, and again, in 2006 (Rakotoarivelo et al. 2011). Between national independence and the present, there have been several critical shifts in environmental policy that are beyond the scope of this study, but have been described in detail elsewhere (e.g., Froger and Méral 2012). Here, we briefly review regulations that influence resource extraction behaviors that have been writ large in Makira Natural Park (MNP), adjacent to our field site in northeastern Madagascar, from formal codified laws to taboos that regulate wildlife consumption. There are varying scales of conservation regulations applicable to natural resource extraction in MNP.

The Makira was gazetted as a protected area in 2005, upgraded to natural park status in 2012, and officially inaugurated as a natural park in 2015. As conservation unfolded, certain forested areas were decentralized from state control to community management and became co-managed by the Wildlife Conservation Society, an international conservation organization that has been operating in Madagascar since the mid-1990s. However, local communities had never recognized state ownership of the forest, not least because of a lack of state involvement as well as very minimal monitoring and enforcement of conservation policies. Before transferring the management of forest areas to the communities surrounding the Makira, the Wildlife Conservation Society created and implemented dina, a term conventionally used by Merina (the dominant ethnic group in Madagascar) to mean community laws. These dina were traditionally drawn from social norms and historical practice by the Merina, but locally they followed from existing national legislation and proscribed the hunting of all primate and carnivore species in the forest. Also outlawed were the hunting of certain tenrec and bat species outside of a particular legalized season or through specific methods such as snares, traps, and hunting at night (Rakotoarivelo et al. 2011).

These new systems of controls over local peoples transformed their identities and changed the character of local resource collection over time. Hunting wildlife for food had been practiced in this area for millennia with no sense of misdeed. The increased attention and management under state law transformed community members' relationship with their environment by imposing a sense of crime and malfeasance on traditions and customs to which they felt entitled, very similar to patterns observed in Tanzania by Neumann (1998). As a result, local peoples felt a sense of fear and wrongdoing for participating in traditional livelihood activities such as hunting (Neumann 1998). Furthermore, people in this region were hardly unregulated resource consumers: they operated with a system of ritualized traditional regulation (i.e., taboos or $f a d y$ ).

The concept of fady in Madagascar is exceedingly complex. In an attempt to clarify some of the definitional intricacies that are not always apparent to outsiders, it is important that we clarify differences between formal and informal uses of the term fady in Madagascar. Formal use of the term indicates a taboo that must be obeyed for spiritual or moral reasons. In contrast, informal use can describe actions that are either socially unacceptable or do not follow proper custom or convention (fomba). Furthermore, there are community-based and individual-based systems of taboos. Community-based taboos use a more contemporary, democratic method of selecting forbidden actions in the collective interest, thus involving an informal sense of the word fady, meaning forbidden rather than taboo. Community-based taboos are different than all other types in that they incur monetary penalties rather than fear of supernatural retribution, similar to what is described by Tengö et al. (2007) in the Androy region of Madagascar.

Here, we do not consider the informal usage of fady in our analysis. We focus on personal and familial wildlife consumption taboos and examine their stability over time and what social factors drive change. Whereas taboos are more collective in other parts of the world, fady in Madagascar are famously individuated, labile, and responsive to experience as it unfolds. Therefore, they are an excellent subject with which to study such forms of change.

\section{METHODS}

\section{Study site}

Golden and his Malagasy research collaborators conducted research in 26 communities throughout forested regions adjacent to MNP in northeastern Madagascar. This forest covers 371,217 ha of lowland and mid-altitude rainforest and represents the largest remaining tract of contiguous forest in Madagascar (Golden 2009). It is one of the most biologically diverse ecosystems in Madagascar and is home to 2 of the 18 major ethnolinguistic groups in Madagascar: the Betsimisaraka in the east and south, and the Tsimihety in the north and west (Golden 2009). Both the Betsimisaraka and Tsimihety in this region are almost exclusively agriculturalists. The Tsimihety tend to inhabit the more interior and remote regions within MNP. The entire region is characterized by a lack of media (no newspapers, no television programming, and only one or two radio stations). 


\section{Data collection}

Between 2005 and 2011, Golden and collaborators conducted annual semi-structured interviews in 861 households within 26 communities. Households were sampled using systematic random sampling from a census list generated by the research team. The survey was administered only to the male heads of households because this was the target sample to obtain information on hunting behavior. Women's taboos are not always the same as men's, but in Malagasy culture, when a man and woman live together as a couple, and especially once they have children, they will often respect each other's taboos, and the children will obey both. However, the husband and wife will also discard certain taboos that become overly burdensome through this merger (i.e., reducing numbers of taboos for working days; Brown 1999). This gender bias limits the results presented to statistical associations relating to men and not to women, although there has been research suggesting that women's taboos are not different from men's in number or content, but may be adhered to more strongly (Lambek 1992).

It is important that we use the individual as the unit of analysis in our study because we aim to dispel prevailing beliefs, particularly held within the environmental and development communities, that the system of taboos is monolithic and collective within ethno-linguistic groups or communities (e.g., Mittermeier et al. 2010, Sodikoff 2012). This perspective fails to acknowledge that, in contrast with practices of this kind in many other places, Malagasy fady are often distinctively personal in nature and mode of transfer and arise out of nuances of individual experience. People share beliefs in taboos as a form, even though there is considerable variation in their content at any moment and over time. The substance of taboos changes with the nature of experience, and it is essential to recognize that variation within the constellation of taboos does not imply dissolution of taboos as a scheme of practice. Taboos are a dynamic expression of personal and family biographies and micro-histories of their ongoing relationship with the local environment. They are a kind of contextual memory. For instance, a respondent may report that he has a food taboo for eating eel because, in the past, one of his ancestors ate eel and his skin developed sores and he died. In a story like this, the food taboo was recorded for quantitative analysis, and the story was also recorded for qualitatively exploring the contextual dimensions of the taboo. This is the basis for our study design and analysis.

Interviews were conducted in respondents' homes, lasting for 45 min to $1 \mathrm{~h}$. They were conducted in Betsimisaraka or Tsimihety, the local dialects. The survey covered numerous topics, including household membership and wealth, resource extraction behaviors, educational achievement, and religious and ethnic group affiliation, among other socio-demographic characteristics. It also touched on a variety of additional questions concerning wildlife harvest (Golden 2009, Brashares et al. 2011, Golden et al. 2014), ethnomedicinal use (Golden et al. 2012a), and the eating of nonfood items (i.e., pica and amylophagy; Golden et al. 2012b). The local research team also obtained historical information on the head of household's place of birth and the number of years since he had arrived in his current community. Quantitative information on the household-level annual consumption rates of individual wildlife species was collected each year and has been validated as an accurate survey instrument (Golden et al. 2013).
During the more unstructured sections of the interview, respondents were asked the reasons why they restricted consumption of certain species of wildlife and were requested to list all of their consumption-based taboos (collected only during the first year of the survey). In Malagasy culture, people can very quickly recount a list of their food taboos. This individual record of taboos can be compared with the annual recall of wildlife species consumed to determine adherence to taboos. If an interviewee could recount the story about the origin of a taboo, it was recorded in the local language. Golden and his Malagasy research collaborators also collected a variety of information on taboos and the wider cosmology of those with traditional beliefs in this region (Golden 2014). This research, gathered over the course of seven years, elucidated the local complexity of food taboos.

\section{Variable creation and analysis}

We created categorical variables for ethnic group (Betsimisaraka, Tsimihety, and other), education (none, primary, middle, and high school), and religion (Catholic, Protestant, Adventist, Traditional, and other). No subject of our research in MNP had attended university. There is an absence of anyone practicing Islam in our sample, and this reflects the larger religious composition of the rural regions. Protestantism is almost entirely FJKM (The Church of Jesus Christ in Madagascar), a nationwide Reformed Protestant denomination. We note that when Malagasy self-identify as not having a formal religion, this means that they abide solely by traditional beliefs, which should be considered a religion in its own right; these respondents were categorized as Traditional. We also created a binary variable for whether or not the male head of household was born in his current community of residence. Finally, we calculated a continuous variable for age and for the number of years since the male head of household had arrived in his current community (see Table 1 for descriptive statistics of all variables). We aimed to explore the socio-demographic correlates of the number of wildlife consumption taboos present and the rate of nonadherence to wildlife consumption taboos. We conducted a generalized multivariable linear regression with which we explored the association

Table 1. Population descriptive statistics. $N=861$ individuals.

\begin{tabular}{llc}
\hline \hline Variable category & Variable description & Prevalence \\
\hline Ethnicity & Betsimisaraka & $27.6 \%$ \\
& Tsimihety & $67.3 \%$ \\
& Other (extra-local & $5.1 \%$ \\
group) & \\
Religion & Traditional & $75.7 \%$ \\
& Catholic & $10.1 \%$ \\
& Protestant & $12.6 \%$ \\
& Adventist & $1.4 \%$ \\
Education & Other & $0.2 \%$ \\
& Primary school & $52.7 \%$ \\
& Middle school & $7.8 \%$ \\
& High school & $2.4 \%$ \\
Born in community & University & $0.0 \%$ \\
Residency length & & $37.1 \%$ \\
Age & & $41.7 \%$ \\
\hline
\end{tabular}


of various socio-demographic correlates in determining the number of wildlife consumption taboos that the male head of household obeyed and did not obey. All statistical analyses were performed in STATA/SE v. 13.0 (StataCorp, College Station, Texas, USA).

\section{RESULTS}

\section{Taboo transmission and retention}

There are three types of taboos (fady): ancestral (fadin-drazana), self-imposed, and those received through spiritual command. During extensive research on taboos throughout the area, we found no example of any single taboo that was present throughout an entire ethno-linguistic group, and only two examples of a taboo that was consistent throughout an entire community. This rarity in the communal sharing of a given taboo has also been found in South America (McDonald 1977). Taboos were most commonly inherited from parents, both mother and father, and passed down through generations. These generational and bilateral types of taboos tended to be respected and observed by all children and could not be ignored. For this reason, they tend to demark kin groups and lines of descent. During traditional Malagasy marriages (sintaka) in this region, there is a ritual called orambato, through which the eldest member from each kinship line (always a direct blood-related member) formalizes the union by sharing the taboos from both the male and female sides, ensuring that the social boundaries harmonize rather than aggravate an existing social order. These ancestral taboos are one example of what von Heland and Folke (2014:252) call a "social contract with the ancestors," which demonstrates how people faced with change and uncertainty behave to promote resilience. Self-imposed taboos, typically precipitated by a negative experience, could be dismissed after a long period when the individual again felt comfortable that there was no longer risk involved in a given behavior.

Other than hereditary transmission and self-imposition, the origin of many taboos is from ombiasa and kalanoro (Fig. 1; see Golden 2014 for detailed discussion). Ombiasa are human spirit mediums who can communicate the wishes and commands of the ancestors (razana). Kalanoro are beneficent spirits that often inhabit rivers or caves; they tend to be envisioned as women with very long hair and fingernails who eat crabs, have reversed feet (heels in front, toes in the back), and are very short like dwarves (locally known as vazimba). These spirits are the entities that bestow taboos upon local people in visions or in dreams. It is important to note that kalanoro are restricted to forest areas, demonstrating an intimate connection between local Malagasy spiritual values and the condition of the surrounding environment. Vividly present in the local imagination, the appearances of these spirits are consistently rendered by local artists in arresting images (Fig. 1). If the forest were to be degraded beyond restoration, local Malagasy contend that the kalanoro would disappear.

Of the 861 heads of household surveyed, $5.0 \%$ had no food taboos. For the remaining individuals, we recorded 6166 taboos. Of these, approximately $79 \%$ (4857 taboos) involved wildlife species, for which we also had consumption data (Table 2). For many of these heads of household, we collected up to seven years of longitudinal data (median $=5 \mathrm{yr}$ ) and were able to observe the degree to which a taboo was adhered to over time. On average, an individual had a median of six food taboos. Of the 4857 wildlife consumption taboos we documented, approximately $3.0 \%$ were not adhered to over the study period. These 145 taboos not adhered to were spread across 93 individuals, demonstrating that it was not just a small group of individuals who did not adhere to taboos, but $>10 \%$ of the surveyed population. Reasons for not adhering to originally stated taboos could include accidental consumption (i.e., served a meal at a friend's home), dismissal of the taboo for its inconvenience, or no longer believing in the consequences of transgressing the taboo. We also found that the presence of an origin story for a given taboo made an individual nearly seventimes more likely to adhere to it (odds ratio $=6.7,95 \%$ CI 5.3-8.4).

Fig. 1. Two depictions of the kalanoro, beneficent spirits that often inhabit rivers or caves. (A) Depiction by renowned Malagasy artist Jean-Nirina Razafindralambo. (B) Depiction by local community member Distin Betora.

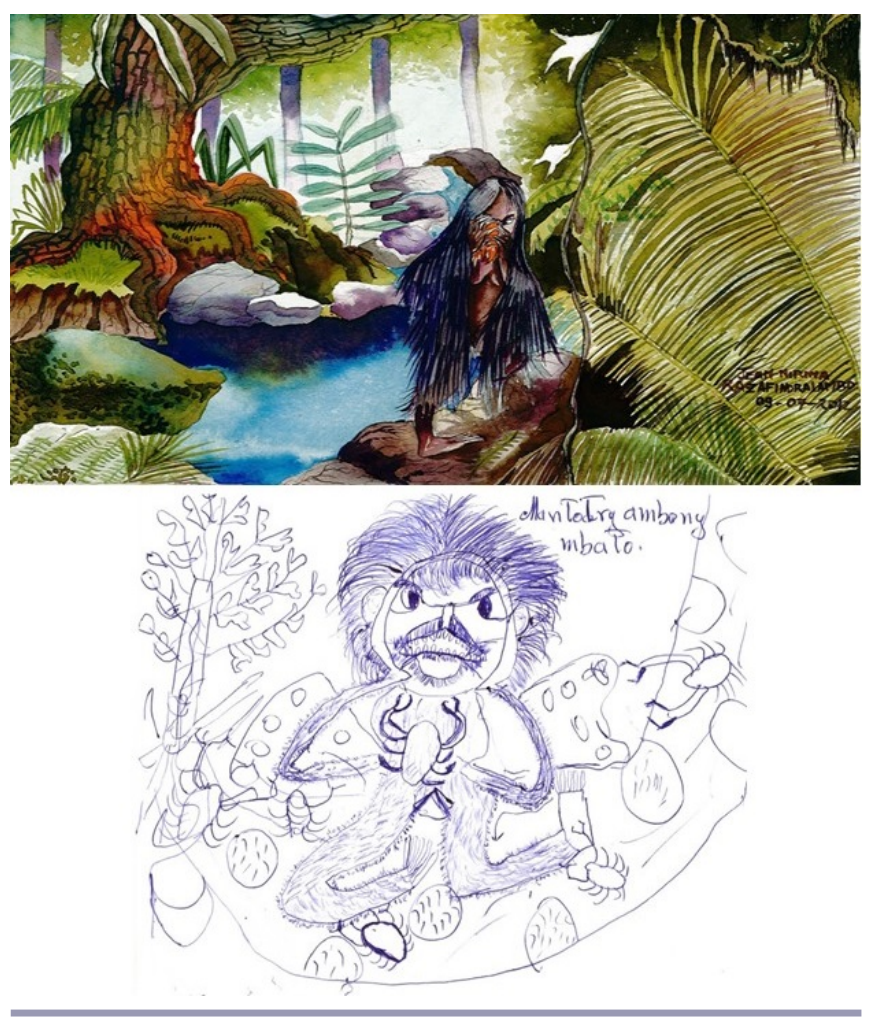

\section{Drivers of taboo nonadherence}

We investigated three possible phenomena that have been claimed to drive social transformation and cultural dissolution. We examined whether patterns of migration, modernization, and the spread of Western religion can explain the number of taboos each individual has, and we tracked trends in nonadherence to taboos. In general, an individual's age, ethno-linguistic group, and religion influenced the number of taboos present. An individual's ethnolinguistic group and whether or not he was born in his current community predisposed him to adhering to the taboos (Table 3 ).

\section{Migration}

In several historical examples of communal resource governance, the arrival of outsiders was seen as anathema to effective resource management, and the exclusion of outsiders such as immigrants 
Table 2. Population prevalence of wildlife species that have consumption-based taboos in the Makira Natural Park, Madagascar.

\begin{tabular}{|c|c|c|c|}
\hline Consumption taboo & Scientific name & Population prevalence $\dagger$ & IUCN status: \\
\hline Hornless zebu§ & Bos indica (hornless version) & $55.30 \%$ & N/A \\
\hline Hedgehog tenrec & Setifer setosus & $45.30 \%$ & $\mathrm{LC}$ \\
\hline Domesticated cat & Felix catus & $31.80 \%$ & N/A \\
\hline Chickpeas§ & Cicer arietinum & $28.60 \%$ & N/A \\
\hline Octopus & Octopus cyanea & $27.80 \%$ & N/A \\
\hline Blue coua & Coua caerulea & $23.20 \%$ & LC \\
\hline Indri & Indri indri & $23.10 \%$ & $\mathrm{CR}$ \\
\hline Eels & & $21.80 \%$ & N/A \\
\hline Crested drongo & Dicrurus forficatus & $19.90 \%$ & $\mathrm{LC}$ \\
\hline Bush pig & Potamochoerus larvatus & $18.70 \%$ & $\mathrm{LC}$ \\
\hline Insectivorous bats & & $18.20 \%$ & N/A \\
\hline Madagascar blue pigeon & Alectroenas madagascariensis & $17.50 \%$ & LC \\
\hline Flying fox & Pteropus rufus & $15.80 \%$ & VU \\
\hline Fern type & Stenochlaena sp. & $15.40 \%$ & N/A \\
\hline Taro leaves & Colocasia esculenta & $14.30 \%$ & N/A \\
\hline Madagascar magpie robin & Copsychus albospecularis & $13.90 \%$ & $\mathrm{LC}$ \\
\hline Eastern woolly lemur & Avahi laniger & $12.80 \%$ & EN \\
\hline Madagascan rousette & Rousettus madagascariensis & $12.50 \%$ & NT \\
\hline Malagasy coucal & Centropus toulou & $11.10 \%$ & LC \\
\hline Aye-aye & Daubentonia madagascariensis & $11.10 \%$ & $\mathrm{EN}$ \\
\hline Peanuts & Arachis hypogaea & $10.50 \%$ & N/A \\
\hline All round things§ & & $10.20 \%$ & N/A \\
\hline Green sea turtle & Chelonia mydas & $10.00 \%$ & $\mathrm{EN}$ \\
\hline Insect species & Pyrops (Zanna) tenebrosa & $9.30 \%$ & N/A \\
\hline Sharks and rays & & $9.70 \%$ & N/A \\
\hline All lemurs & & $8.90 \%$ & N/A \\
\hline White-fronted brown lemur & Eulemur albifrons & $8.60 \%$ & EN \\
\hline Ringtailed mongoose & Galidia elegans & $7.80 \%$ & LC \\
\hline Fosa & Cryptoprocta ferox & $7.70 \%$ & VU \\
\hline Eastern bamboo lemur & Hapalemur griseus & $7.70 \%$ & VU \\
\hline Red-bellied lemur & Eulemur rubriventer & $7.10 \%$ & VU \\
\hline Madagascar cisticola & Cisticola cherina & $7.00 \%$ & $\mathrm{LC}$ \\
\hline Spotted zebu & Bos indica (spotted version) & $7.00 \%$ & N/A \\
\hline $\begin{array}{l}\text { Multiple species of saltwater fish } \\
\text { (combined total) }\end{array}$ & & $6.70 \%$ & N/A \\
\hline Malagasy turtle dove & Nesoenas picturatus & $6.50 \%$ & LC \\
\hline Madagascar green pigeon & Treron australis & $6.20 \%$ & LC \\
\hline East African black mud turtle & Pelusios subniger & $5.70 \%$ & $\mathrm{LC}$ \\
\hline White mushrooms & & $5.60 \%$ & N/A \\
\hline Seal's sportive lemur & Lepilemur seali & $5.50 \%$ & EN \\
\hline Black and white ruffed lemur & Varecia variegata & $5.20 \%$ & $\mathrm{CR}$ \\
\hline Silky sifaka & Propithecus candidus & $5.00 \%$ & $\mathrm{CR}$ \\
\hline No taboo $(f a d y)$ & & $7.00 \%$ & \\
\hline Nile crocodile & Crocodylus niloticus & $4.90 \%$ & LC \\
\hline Mouse lemurs & Microcebus sp. & $4.90 \%$ & $\mathrm{LC}$ \\
\hline Red ruffed lemur & Varecia rubra & $4.80 \%$ & $\mathrm{CR}$ \\
\hline Lesser Indian civet & Viverricula indica & $4.60 \%$ & $\mathrm{LC}$ \\
\hline Zebu kidney & & $4.40 \%$ & N/A \\
\hline Madagascar crested ibis & Lophotibis cristata & $4.20 \%$ & NT \\
\hline Dwarf lemurs & Cheirogaleus sp. & $3.80 \%$ & N/A \\
\hline Falanoka & Eupleres goudoti & $3.30 \%$ & NT \\
\hline Goats & Capra sp. & $3.00 \%$ & N/A \\
\hline Common tenrec & Tenrec ecaudatus & $3.00 \%$ & $\mathrm{LC}$ \\
\hline
\end{tabular}

$\dagger$ Population prevalence is the percentage of surveyed male head of households who abide by particular taboos.

\$The Internation Union for the Conservation of Nature status of species is listed for those with information available (IUCN 2012). Lemur species were assigned a status based on the recent Red List updating from July 2012. $\mathrm{LC}=$ least concern, $\mathrm{VU}=$ vulnerable, $\mathrm{EN}=$ endangered, $\mathrm{CR}=$ critically endangered, N/A = not listed.

$\S$ See Golden and Comaroff (2015) for a description of why round items are a common taboo. 
Table 3. Results of two generalized linear mixed models exploring the socio-demographic correlates of food taboos for number of food taboos and rate of nonadherence to taboos, respectively, by which a male head of household abides.

\begin{tabular}{|c|c|c|c|}
\hline Variable category & Variable description & Number of food taboos $\dagger$ & $\begin{array}{l}\text { Proportion }(\%) \text { of nonadherence to } \\
\text { taboos } \dagger\end{array}$ \\
\hline Ethnic affiliation & Tsimihety & $4.62-6.38^{* * *}$ & $0.03-0.34 *$ \\
\hline (Betsimisaraka is baseline) & Other (extra-local ethnic group) & $-0.42-3.05$ & $0.03-0.63^{*}$ \\
\hline Religion & Catholic & -2.81 to $-0.65^{* *}$ & $-0.23-0.15$ \\
\hline \multirow[t]{2}{*}{ (Traditional is baseline) } & Protestant & -4.69 to $-2.49 * * *$ & $-0.24-0.14$ \\
\hline & Adventist & $-0.72-7.83$ & $-0.22-1.2$ \\
\hline Education & Primary school & $-1.13-0.65$ & $-0.26-0.05$ \\
\hline \multirow[t]{2}{*}{ (No education is baseline) } & Middle school & $-2.39-0.46$ & $-0.41-0.08$ \\
\hline & High school & $-3.27-1.82$ & $-0.19-0.7$ \\
\hline $\begin{array}{l}\text { Born in community } \\
\text { (yes or no) }\end{array}$ & Born in current community & $-1.6-0.47$ & $0.03-0.39 *$ \\
\hline $\begin{array}{l}\text { Residency length in community } \\
\text { (yr) }\end{array}$ & & $-0.01-0.05$ & $-0.007-0.003$ \\
\hline Age (yr) & & -0.08 to $-0.01^{*}$ & $-0.0008-0.004$ \\
\hline
\end{tabular}

or those outside the defined community was seen as the key to successful management (Feeny et al. 1990, Ostrom 1999). The breakdown of exclusive communal-property mechanisms is attributed to population growth, technological change, or economic change, including new market opportunities (Feeny et al. 1990). In Madagascar specifically, migration is considered to be disproportionately responsible for heavier deforestation and natural resource use (e.g., Durbin et al. 2003, Rabemananjara 2014) as well as a driver of cultural dissolution (e.g., Gardner et al. 2013).

Of the two indigenous ethno-linguistic groups in this area, Tsimihety were likely to have five or six more taboos on average than Betsimisaraka (Table 3). In addition, we found that individuals from extra-local ethno-linguistic groups do not have significantly different numbers of food taboos than the indigenous Betsimisaraka (Table 3). Thus, migration from ethnic groups outside of this area does not necessarily reduce the number of wildlife consumption taboos by which people abide. Further, both living in the village in which an individual was born and length of residence in a village were statistically insignificant in determining the number of food taboos he claims (Table 3 ).

Neither indigeneity (membership in either ethno-linguistic group of the Makira region, Betsimisaraka and Tsimihety) nor nativity (whether an individual was born in his current village) was significantly associated with the number of wildlife consumption taboos a head of household had. However, membership in an extra-local ethno-linguistic group approximately doubles the rate of nonadherence to an individual's taboos. Being born outside of one's current community (even if one is of the local ethnic group) is also significantly associated with nonadherence to an individual's taboos (Table 3). Thus, there is evidence that migrants tend to disregard taboos more readily, although still at relatively low rates in this region. It is possible that having an "attachment to place," a variable not measured here, may be responsible for these differences. Place is always at once physical, but mediated by cultural perceptions. Therefore, it is material and meaningful. When we mention attachment to place, we are describing an attachment to a physical place whose meaning is intensified due to the length of an individual's attachment to it. This also opens the possibility that new taboos may develop over time as people establish closer ties with their new environment.

\section{Modernization}

Some recent empirical research has demonstrated that modernization and economic development are associated with a loss of traditional ecological knowledge, both in the Tsimané of the Amazon (Reyes-García et al. 2013) and in a more Western context in Spain (Gómez-Baggethun et al. 2010), among other examples. Without access to longitudinal inter-generational data, our analysis attempted to explore the differential observance of taboos by age through cross-sectional data. We found some evidence of nonadherence to taboos among the young, but we also found that new taboos may be increasing in that population over time. Younger individuals acknowledged significantly more food taboos than older individuals $(P=0.019$; Table 3$)$. This makes intuitive sense because the taboos of both mother and father are often passed down to their children. As migration continues to occur throughout Madagascar, people who are less closely related will intermarry, leading to a more diverse, broader set of taboos passed down to future generations. Similarly, we did not find that an individual's age or educational achievement had a significant influence on rates of adherence to taboos (Table 3). Thus, Madagascar's plans to develop and increase access to education for the general public should not necessarily lead to cultural erosion of taboos. However, it would be interesting to resurvey these communities after a generation to determine the trajectory of these processes.

Studies elsewhere suggest that adherence to tradition changes over the cycle of a lifetime; young people might go through periods of lapse, only to re-assert ties again once they become parents and begin to age. This hypothesis is plausible but cannot be tested using our data because only the heads of households were interviewed, biasing our results to individuals who self-recognized themselves as equipped to assume that role. It is often believed that modernization decreases tradition, as if these two 
phenomena were simply opposed and separate. In fact, the effects of more global integration often increase local practices, intensifying them even as they hybridize them. This is because people respond to shifts in experience (i.e., increased mobility, conflict, anxiety) by deploying local cultural technologies such as fady. However, this process is often accompanied by expanded or innovative approaches to attain cultural resilience in the face of generational shifts.

It is possible that the youth may be economically hungry and more brazen and thus will transgress the dictates of both formal and informal institutions. Gadgil et al. (1993) found that modernization (defined as an integration into global economies, acculturation, and population pressures) led to an erosion of sustainable resource use and relevant indigenous knowledge. Alcorn (1993) questioned this association, arguing that modernization and development can lead to mixed results: either biodiversity defense or destruction. One example of modernization leading to biodiversity destruction is the shift in relationship to land tortoises in southern Madagascar. Lilette (2006) found that primarily technological advancement and the creation of markets for tortoises have changed taboos and led local people to re-negotiate their relationship with this species, both spiritually and economically, from one of taboo to one of opportunity. Lillette (2006) also found that increased capital and market presence drove further extraction of tortoises. In Makira, there was a sense that those with capital should not rely on wildlife for food, this being expressed through a ritual that some local hunters practiced in which they would remove all money from their pockets prior to a hunt, claiming that those with money would not reap benefits from the forest. There appeared to be an understanding with the spiritual order that regulates chance (vintana) and destiny (anjara) such that an individual could only receive what was necessary from the forest. This belief system highlights both a structure of spiritually mediated equity and a potential understanding of sustainability.

The lack of evidence for modernization driving the erosion of taboos could be explained in two ways. First, what appears to be diversity in taboos may not be a downward trajectory implying a beginning (ancestral days with taboos) and an end (modern time with no taboos), but instead is a snapshot of the variability of taboos between people and in the same people over time. Second, because of the transmission system of taboos through both mother and father, increasing movement, migration, and intermarriage actually facilitates development of a broader set of taboos.

\section{Spread of Western religion}

There is currently wide debate about the effect of religious globalization on the adherence to local customary traditions and social behaviors (Meyer 1998, Olupona and Rey 2008). On the one hand, the spread of Western religion has been credited with the degradation of traditional informal institutions that regulate natural resource use in Nigeria (Anoliefo et al. 2003). On the other hand, Gadgil et al. (1993) discuss how religious syncretism did not erode sacred groves and a traditional conservation ethic in India.

In Madagascar, there is also mixed evidence of the role of religion and its effect on traditional values. In some cases, Christianity is believed to erode cultural taboos (Tengö et al. 2007), whereas in other cases, it is believed to have little effect on traditional values and institutions (Lingard et al. 2003). We found that religions of external origin in the Makira were always syncretized with traditional beliefs, but had likely caused a reduction in the number of taboos observed by an individual. On average, Catholics had two fewer taboos and Protestants four fewer taboos than those with traditional beliefs. However, the influence of Western religion and the number of food taboos was not unidirectional. Adventists, although not statistically significant due to a small sample size $(N=7)$, had nearly four more taboos on average than those with traditional beliefs (Table 3 ). Thus, Western religion is not a unitary category and cannot be categorically credited with disrupting taboos in the Makira region, although it does seem as though particular Christian denominations cause reductions in the numbers of observed taboos. Religion, however, does not affect adherence rates to those taboos that an individual maintains following conversion (Table 3). Thus, although religious conversion is related to the dismissal of taboos, religion in this region is still heavily syncretized, and seemingly conflicting attachments can coexist without contradiction such that traditional beliefs are viewed more as custom than religion.

\section{DISCUSSION}

Our results bring us to three main conclusions. First, the heterogeneity of taboos in the local Malagasy culture does not translate into erosion of a previously intact and homogenous taboo system. Second, the ways in which social change affect the stability of taboos are complex and tend to demonstrate that migrants adhere to taboos less strongly than historical inhabitants, suggesting that attachment to place is significant in maintaining such adherence. Only longitudinal study can reveal whether new repertoires of taboos develop over time in migrants' new locales or as youth begin to age. Lastly, Western religion may reduce the number of taboos recognized by an individual, but the increasing inter-marriage of diverse kin groups and cultures may increase the number of taboos a person holds because children draw them from both mother and father.

Some reports in Madagascar have suggested an erosion of taboos (Jones et al. 2008, Jenkins et al. 2011, Sodikoff 2012) but lack the longitudinal evidence to document adequately this type of cultural change. Without a proper understanding of the dynamic nature of taboos and the patterns of their transmission, the presence of taboo heterogeneity in a population is not evidence of erosion. It is certain that there has been hunting in Madagascar for at least 2000 years, since humans first settled on the landscape (Perez et al. 2005). Given that hunting has occurred for millennia, the presence of significant heterogeneity in the coverage of taboos across species should not be interpreted as an erosion of cultural values, but rather as the presence of a dynamic and highly complex system of regulations and sanctions. We did, however, find possible evidence of taboo erosion. Tsimihety were found to have significantly more taboos than their neighbors, the Betsimisaraka. This could be a legacy of colonialism (or the lack thereof), with the Tsimihety among the only ethnic groups in Madagascar to have barred colonization efforts from Europeans, Arabs, and the Merina hierarchy (Wilson 1992). We also found evidence of taboo erosion from a lack of adherence to particular taboos in the present day, although rates of nonadherence were quite low. However, the system of taboo transmission (i.e., receiving taboos from both mother and father) is associated with increases in the 
overall numbers of taboos. Therefore, in an individual lifetime, some taboos may be lost over time, but on a generational time scale, taboos may increase due to the system of transmission.

Taboos may not adequately protect endangered species, but there is evidence in the local belief system that may shed light on conceptualizations of sustainability. Men removing money from their pockets prior to a hunt seems somehow significant, perhaps expressing symbolically the view that harvesting of environmental resources is necessary only for those with real dependence. The inextricable relationship between the integrity of the surrounding environment and the local Malagasy spiritual cosmology (i.e., the need of the kalanoro to live in an intact forest environment) powerfully underlines local people's need for the forest if they are to survive (Golden 2014). It is examples such as these that may facilitate mechanisms for finding synergies in local values and conservation values, and broaden the constituencies for those who support the maintenance of environmental integrity.

\section{Responses to this article can be read online at: http://www.ecologyandsociety.org/issues/responses. $\mathrm{php} / 7589$}

\section{Acknowledgments:}

This work arose from more than a decade of experience in Madagascar, with no possible way to properly recognize and honor all of the people who inspired this work. Although insufficient, we thank all of the local people living near the Makira forest who shared their wisdom and experience, and, in case they ever see this document, misaotra ianareo jiaby amin'ny fanampiana. We thank Louise Fortmann, Christian Kull, Nora Khan, and A. Clare Gupta for reviewing an earlier version of the manuscript.

\section{LITERATURE CITED}

Alcorn, J. B. 1991. Epilogue: ethics, economics and conservation. Pages 317-349 in M. L. Oldfield and J. B. Alcorn, editors. Biodiversity: culture, conservation, and ecodevelopment. Westview Press, Boulder, Colorado, USA.

Alcorn, J. B. 1993. Indigenous peoples and conservation. Conservation Biology 7(2):424-426. http://dx.doi.org/10.1046/ j.1523-1739.1993.07020424.X

Anoliefo, G. O., O. S. Isikhuemhen, and N. R. Ochije. 2003. Environmental implications of the erosion of cultural taboo practices in Awka-South Local Government Area of Anambra State, Nigeria: 1. Forests, trees, and water resource preservation. Journal of Agricultural and Environmental Ethics 16(3):281-296. http://dx.doi.org/10.1023/A:1023680117717

Blanc-Pamard, C. 2009. The Mikea Forest under threat (southwest Madagascar): how public policy leads to conflicting territories. Field Actions Science Reports 3. [online] URL: http:// factsreports.revues.org/341.

Bloch, M. 2001. The ethnohistory of Madagascar. Ethnohistory 48(1-2):293-299. http://dx.doi.org/10.1215/00141801-48-1-2-293

Brashares, J. S., C. D. Golden, K. Z. Weinbaum, C. B. Barrett, and G. V. Okello. 2011. Economic and geographic drivers of wildlife consumption in rural Africa. Proceedings of the National Academy of Sciences 108(34):13931-13936. http://dx.doi. org/10.1073/pnas.1011526108

Brown, M. L. 1999. Authority relations and trust: social cohesion on the eastern Masoala Peninsula, Madagascar. Dissertation. Washington University, St. Louis, Missouri, USA.

Chapin, M. 1991. Losing the way of the Great Father. New Scientist 131:40-44.

Copland, S. 1822. A history of the island of Madagascar. Burton and Smith, London, UK.

Durbin, J., K. Bernard, and M. Fenn. 2003. The role of socioeconomic factors in the loss of Malagasy biodiversity. Pages 142-146 in S. M. Goodman and J. P. Benstead, editors. The natural history of Madagascar. University of Chicago Press, Chicago, Illinois, USA.

Feeny, D., F. Berkes, B. J. McCay, and J. M. Acheson. 1990. The tragedy of the commons: twenty-two years later. Human Ecology 18(1):1-19. http://dx.doi.org/10.1007/BF00889070

Froger, G., and P. Méral. 2012. Towards an institutional and historical analysis of environmental policy in Madagascar. Environmental Policy and Governance 22(5):369-380. http://dx. doi.org/10.1002/eet.1595

Gadgil, M., F. Berkes, and C. Folke. 1993. Indigenous knowledge for biodiversity conservation. Ambio 22(2-3):151-156.

Gardner, C. J., B. Ferguson, F. Rebara, and A. N. Ratsifandrihamanana. 2008. Integrating traditional values and management regimes into Madagascar's expanded protected area system: the case of Ankodida. Pages 92-103 in J.-M. Mallarach, editor. Protected landscapes and cultural and spiritual values. Kasparek Verlag, Heidelberg, Germany.

Gardner, C. J., M. E. Nicoll, T. Mbohoahy, K. L. Oleson, A. N. Ratsifandrihamanana, J. Ratsirarson, L.-A. R. de Roland, M. Virah-Sawmy, B. Zafindrasilivonona, and Z. G. Davies. 2013. Protected areas for conservation and poverty alleviation: experiences from Madagascar. Journal of Applied Ecology 50 (6):1289-1294. http://dx.doi.org/10.1111/1365-2664.12164

Golden, C. D. 2009. Bushmeat hunting and use in the Makira Forest north-eastern Madagascar: a conservation and livelihoods issue. Oryx 43(3):386-392. http://dx.doi.org/10.1017/S0030605309000131

Golden, C. D. 2014. Spiritual roots of the land: hierarchy and relationships of the religious cosmologies of humans and their environment in the Maroantsetra region of Madagascar. Worldviews: Global Religions, Culture, and Ecology 18(3):255-268. http://dx.doi.org/10.1163/15685357-01802010

Golden, C. D., M. H. Bonds, J. S. Brashares, B. J. R. Rasolofoniaina, and C. Kremen. 2014. Economic valuation of subsistence harvest of wildlife in Madagascar. Conservation Biology 28(1):234-243. http://dx.doi.org/10.1111/cobi.12174

Golden, C. D., and J. Comaroff. 2015. The human health and conservation relevance of food taboos in northeastern Madagascar. Ecology and Society 20(2): 42. http://dx.doi. org/10.5751/es-07590-200242

Golden, C. D., B. J. R. Rasolofoniaina, E. J. G. Anjaranirina, L. 
Nicolas, L. Ravaoliny, and C. Kremen. 2012a. Rainforest pharmacopeia in Madagascar provides high value for current local and prospective global uses. PLoS One 7: e41221. http://dx. doi.org/10.1371/journal.pone.0041221

Golden, C. D., B. J. R. Rasolofoniaina, R. Benjamin, and S. L. Young. 2012b. Pica and amylophagy are common among Malagasy men, women and children. PLoS One 7: e47129. http:// dx.doi.org/10.1371/journal.pone.0047129

Golden, C. D., R. W. Wrangham, and J. S. Brashares. 2013. Assessing the accuracy of interviewed recall for rare, highly seasonal events: the case of wildlife consumption in Madagascar. Animal Conservation 16(6):597-603. http://dx.doi.org/10.1111/ acv. 12047

Gómez-Baggethun, E., S. Mingorría, V. Reyes-García, L. Calvet, and C. Montes. 2010. Traditional ecological knowledge trends in the transition to a market economy: empirical study in the Doñana Natural Areas. Conservation Biology 24(3):721-729. http://dx.doi.org/10.1111/j.1523-1739.2009.01401.x

Horning, N. R. 2012. Debunking three myths about Madagascar's deforestation. Madagascar Conservation and Development 7 (3):116-119. [online] URL: http://journalmcd.com/index.php/ mcd/article/view/mcd.v7i3.3/314.

IUCN [International Union for Conservation of Nature]. 2012. The IUCN redlist of threatened species interactive database. IUCN, Cambridge, UK. [online] URL: http://www.iucnredlist. org/.

Jenkins, R. K. B., A. Keane, A. R. Rakotoarivelo, V. Rakotomboavonjy, F. H. Randrianandrianina, H. J. Razafimanahaka, S. R. Ralaiarimalala, and J. P. G. Jones. 2011. Analysis of patterns of bushmeat consumption reveals extensive exploitation of protected species in eastern Madagascar. PLoS One 6(12): e27570. http://dx.doi.org/10.1371/journal.pone.0027570

Jones, J. P. G., M. M. Andriamarovololona, and N. Hockley. 2008. The importance of taboos and social norms to conservation in Madagascar. Conservation Biology 22(4):976-986. http://dx.doi. org/10.1111/j.1523-1739.2008.00970.x

Kaufmann, J. C., and S. Tsirahamba. 2006. Forests and thorns: conditions of change affecting Mahafale pastoralists in southwestern Madagascar. Conservation and Society 4 (2):231-261.

Kull, C. A. 2000 Deforestation, erosion, and fire: degradation myths in the environmental history of Madagascar. Environment and History 6(4):423-450. http://dx.doi.org/10.3197/096734000129342361

Lambek, M. 1992. Taboo as cultural practice among Malagasy speakers. Man 27(2):245-266. http://dx.doi.org/10.2307/2804053

Lilette, V. 2006. Mixed results: conservation of the marine turtle and the red-tailed tropicbird by Vezo semi-nomadic fishers. Conservation and Society 4(2):262-286.

Lingard, M., N. Raharison, E. Rabakonandrianina, J.-A. Rakotoarisoa, and T. Elmqvist. 2003. The role of local taboos in conservation and management of species: the radiated tortoise in southern Madagascar. Conservation and Society 1(2):223-246.

McDonald, D. R. 1977. Food-taboos: primitive environmental protection agency (South America). Anthropos 72(5-6):734-748. [online] URL: http://www.jstor.org/stable/40459182.

Meyer, B. 1998. 'Make a complete break with the past.' Memory and post-colonial modernity in Ghanaian Pentecostalist discourse. Journal of Religion in Africa 28(3):316-349. http://dx. doi.org/10.1163/157006698X00044

Minten, B., and C. B. Barrett. 2008. Agricultural technology, productivity, and poverty in Madagascar. World Development 36 (5):797-822. http://dx.doi.org/10.1016/j.worlddev.2007.05.004

Mittermeier, R. A., W. R. Konstant, F. Hawkins, E. E. Louis, O. Langrand, J. Ratsimbazafy, R. Rasoloarison, J. U. Ganzhorn, S. Rajaobelina, I. Tattersall, and D. M. Meyers. 2010. Lemurs of Madagascar. Third edition. Conservation International, Washington, D.C., USA.

Neumann, R. P. 1998. Imposing wilderness: struggles over livelihood and nature preservation in Africa. University of California Press, Berkeley, California, USA.

Olupona, J. K., and T. Rey, editors. 2008. Òrişà devotion as world religion: the globalization of Yorùbá religious culture. University of Wisconsin Press, Madison, Wisconsin, USA.

Ostrom, E. 1999. Coping with tragedies of the commons. Annual Review of Political Science 2:493-535. http://dx.doi.org/10.1146/ annurev.polisci.2.1.493

Patel, E. R. 2007. Logging of rare rosewood and palisandre (Dalbergia spp.) within Marojejy National Park, Madagascar. Madagascar Conservation and Development 2:11-16. [online] URL: http://journalmcd.com/index.php/mcd/article/view/234/189.

Perez, V. R., L. R. Godfrey, M. Nowak-Kemp, D. A. Burney, J. Ratsimbazafy, and N. Vasey. 2005. Evidence of early butchery of giant lemurs in Madagascar. Journal of Human Evolution 49 (6):722-742. http://dx.doi.org/10.1016/j.jhevol.2005.08.004

Rabemananjara, Z. H. 2014. Migration causing forest degradation in Madagasar: prevention or adaptation to the effects? Pinnacle Natural Resources and Conservation 1(1): pnrc_130, 194-201. [online] URL: http://pjpub.org/pnrc/ pnrc 130.pdf.

Rakotoarivelo, A. R., J. H. Razafimanahaka, S. Rabesihanaka, J. P. G. Jones, and R. K. B. Jenkins. 2011. Lois et règlements sur la faune sauvage à Madagascar: progrès accomplis et besoins du futur. Madagascar Conservation and Development 6(1):37-44. http://dx.doi.org/10.4314/mcd.v6i1.68063

Rakotomanga, H. M. 2011. Democratic transition in Madagascar, Malawi, and Mozambique. Dissertation. Texas State University, San Marcos, Texas, USA. [online] URL: https://digital.library. txstate.edu/handle/10877/2550.

Rasolofoson, D., G. Rakotondratsimba, O. Rakotonirainy, L. M. A. Rakotozafy, J. H. Ratsimbazafy, L. Rabetafika, and R. M. Randrianarison. 2007. Influences des pressions anthropiques sur les lémuriens d'Antantaka, dans la partie Est du plateau du Makira, Maroantsetra, Madagascar. Madagascar Conservation and Development 2(1):21-27. [online] URL: http://journalmcd. com/index.php/mcd/article/view/236/191.

Reyes-García, V., M. Guèze, A. C. Luz, J. Paneque-Gálvez, M. J. Macía, M. Orta-Martínez, J. Pino, and X. Rubio-Campillo. 2013. Evidence of traditional knowledge loss among a contemporary 
indigenous society. Evolution and Human Behavior 34(4):249-257. http://dx.doi.org/10.1016/j.evolhumbehav.2013.03.002

Ruud, J. 1960. Taboo: a study of Malagasy customs and beliefs. Oslo University Press, Oslo, Norway.

Scales, I. R. 2011. Farming at the forest frontier: land use and landscape change in western Madagascar, 1896-2005. Environment and History 17(4):499-524. http://dx.doi. org/10.3197/096734011X13150366551481

Schachenmann, P. 2006. Spiritual values in Madagascar: the starting point for endogenous conservation initiatives. Mountain Research and Development 26(4):323-327. http://dx.doi. org/10.1659/0276-4741(2006)26[323:SVIM]2.0.CO;2

Sodikoff, G. M. 2012. Totem and taboo reconsidered: endangered species and moral practice in Madagascar. Pages 67-88 in G. M. Sodikoff, editor. The anthropology of extinction: essays on culture and species death. Indiana University Press, Bloomington, Indiana, USA.

Stifel, D., M. Fafchamps, and B. Minten. 2011. Taboos, agriculture and poverty. Journal of Development Studies 47 (10):1455-1481. http://dx.doi.org/10.1080/00220388.2011.561322

Tengö, M., K. Johansson, F. Rakotondrasoa, J. Lundberg, J.-A. Andriamaherilala, J.-A. Rakotoarisoa, and T. Elmqvist. 2007. Taboos and forest governance: informal protection of hot spot dry forest in southern Madagascar. Ambio 36(8):683-691. http:// dx.doi.org/10.1579/0044-7447(2007)36[683:TAFGIP]2.0.CO;2

UNDESA [United Nations Department of Economic and Social Affairs]. 2013. World population prospects: the 2010 revision. UNDESA, New York, New York, USA. [online] URL: http://esa. un.org/unpd/wpp/Documentation/pdf/WPP2012 VolumeI Comprehensive-Tables.pdf.

von Heland, J., and C. Folke. 2014. A social contract with the ancestors - culture and ecosystem services in southern Madagascar. Global Environmental Change 24:251-264. http://dx. doi.org/10.1016/j.gloenvcha.2013.11.003

Wilson, P. J. 1992. Freedom by a hair's breadth: Tsimihety in Madagascar. University of Michigan Press, Ann Arbor, Michigan, USA.

Zeller, M., C. Lapenu, B. Minten, E. Ralison, D. Randrianaivo, and C. Randrianarisoa. 1999. Pathways of rural development in Madagascar: an empirical investigation of the critical triangle between environmental sustainability, economic growth and poverty alleviation. Quarterly Journal of International Agriculture 2:105-127.

Zounmenou, D. 2009. Madagascar's political crisis: what options for the mediation process? African Security Studies 18(4):71-75. http://dx.doi.org/10.1080/10246029.2009.9627558 